\title{
Revisitando a experiência de cooperativismo de Mondragón a partir da perspectiva da ecossocioeconomia
}

\section{Revisiting the Mondragón Cooperative Experience from the Perspective of Eco Socio-economy}

\author{
Carlos Alberto Cioce SAMPAIO* \\ Valdir FERNANDES ${ }^{* *}$ \\ Joseba Azkarraga ETXAGIBEL ${ }^{* * *}$ \\ Larraitz Altuna GABILONDO****
}

\begin{abstract}
RESUMO
Essa é uma história, em curso, que não deve ser confundida com uma mera trajetória exitosa de uma corporação de empresas cooperativas. Mondragón Corporação Cooperativa (MCC), sétimo maior grupo empresarial privado da Espanha, com mais de 100.000 trabalhadores e que atua em setores nos quais, geralmente, atuam empresas privadas ou públicas, deve ser visto sempre sob a perspectiva da economia social. Este artigo tem como objetivo resgatar os princípios considerados pelo idealizador da MCC, José María Arizmendiarrieta, que podem subsidiar as adaptações necessárias ao enfoque socioeconômico, transcritos nos 10 princípios da MCC, bem como as suas implicações ideológicas e práticas, considerando o paradigma da sustentabilidade, por meio do enfoque da ecossocioeconomia. Esta pesquisa valeu-se de observação participativa, com duração de três meses, na qual se vivenciou a experiência a partir de entrevistas, visitas e de dados secundários. A conclusão é que, atualmente, tal inspiração está debilitada diante do risco de um corporativismo cooperativo que deseja se autopreservar e da lógica de autorregulação do mercado. Contudo, a experiência mostra fôlego, com suas inovações inter e extraorganizacionais, com senso crítico e pragmatismo que superam a mera crítica, ante a ideologia que se tornou estéril, ao mesmo tempo em que preserva a inspiração do seu fundador.
\end{abstract}

Palavras-chave: cooperativismo; gestão socioambiental; ecossocioeconomia.

\footnotetext{
" Doutor em Engenharia de Produção (UFSC). Professor do Departamento de Turismo e do Programa de Pós-Graduação (PPG) em Meio Ambiente e Desenvolvimento da Universidade Federal do Paraná (UFPR). Pesquisador/CNPq. Membro da Comissão de Área em Ciências Ambientais (CACiAmb)/CAPES. E-mail: carlos.cioce@gmail.com

** Doutor em Engenharia Ambiental (UFSC). Professor dos Programas de Pós-Graduação em Gestão Ambiental da Universidade Positivo (UP) e Organizações e Desenvolvimento da FAE. E-mail valdir.fernandes@me.com.

*** Doutor em Sociologia (Universidad del País Vasco). Pesquisador do Instituto de Estudos Cooperativos LANKI e Professor de Graduação, Especialização e Doutorado da Faculdade de Humanidades e Ciências da Educação (HUHEZI) da Universidade de Mondragón. E-mail: jazkarraga@mondragon.edu

***** Mestre em Estudos Latinoamericanos (Universidad Nacional Autónoma de México) e Doutoranda em Sociologia (Universidad Pública de Navarra). Pesquisadora do Instituto de Estudos Cooperativos LANKI e Professora da Faculdade de HUHEZI da Universidade de Mondragóngadora de LANKI. E-mail: altuna@mondragon.edu
} 


\begin{abstract}
This is a current history that should not be confused with a single successful trajectory of a corporation of cooperative companies. Mondragon Cooperative Corporation, the seventh biggest private enterprise group from Spain, with more than 100,000 workers, which is inserted in sectors generally operated by private or public companies, must always be seen under the perspective of the social economy. The objective of this article is to reflect on the cooperative experience of Mondragon under the perspective of corporative socio environmental management. This research consisted of a 3-month participative observation through the experience from interviews, visits and secondary data. The conclusion is that currently such inspiration is weakened by the risk of a cooperative corporatism that seeks self-preservation and of the self-regulatory logic of the market. However, the experience shows strength, with inter and extra organizational innovations, critical thinking and pragmatism that surpasses mere criticism, before the ideology that has become barren while it preserves the inspiration of its founder.
\end{abstract}

Keywords: cooperative; socio environmental management; eco socio-economy

\section{Introdução}

A trajetória exitosa das cooperativas de Mondragón (Mondragón Corporación Cooperativa - MCC), se olhada de modo superficial, poderia ser facilmente confundida como uma mera trajetória de sucesso de uma corporação, o sétimo maior grupo empresarial privado da Espanha, com mais de 100.000 trabalhadores, atuando nos setores financeiro, industrial, distribuição e educação. Todavia, esta superficialidade deixaria escapar o que há de mais rico e paradigmático nesta experiência. Sua filosofia, seu espírito, seu projeto de transformação e de emancipação, forjado em pleno regime autoritário, sob a liderança de um religioso, o Padre José María Arizmendiarrieta, na década de $1940 .{ }^{1}$ Na ocasião, emerge a primeira cooperativa, conhecida hoje como Fagor Eletrodomésticos, que coincide com projeto educativo, cuja herança direta é a Faculdade Politécnica de Engenharia da Universidade de Mondragón. Como a motivação não era fundar uma utopia, houve a transformação em uma experiência emblemática que desperta constante reflexão acerca do seu significado (MCC, 2006; ALTUNA, 2008, p. 18).

O cooperativismo de Mondragón fundamenta-se em 10 princípios, que constituem a sua base de funcionamento e ao mesmo tempo se materializam numa prática, ou numa ascese, que é síntese de uma ética, a ética católica de Arizmendiarrieta. Estes princípios são: livre adesão; organização democrática; soberania do trabalho; instrumentalização e subordinação do capital; gestão participativa; solidariedade distributiva; cooperação; transformação social; universalidade e educação.

Para Arizmendiarrieta (1984), porém, a educação devia ser o início de tudo. Antes de criar cooperativas, há que se ter pessoas colaborativas. Nas conversas entre os sócios da cooperativa, porém, não é incomum que isto seja esquecido, centrando-se muito mais nas cooperativas e menos nas pessoas. Entretanto, se há uma característica histórica que diferencia a experiência da cooperativa mondragonesa de outras trajetórias é exatamente o olhar educacional e emancipatório.

O final do século XX parece ter trazido a consciência dos limites do desenvolvimento, em função das frequentes catástrofes naturais e da exaustão dos recursos naturais. Esta nova consciência questiona e impõe limites, tanto aos modelos empresariais essencialmente capitalistas como à cultura cooperativa de Mondragón. O crescimento econômico já não é só virtude, mas também é causa de profunda inquietação e de incertezas.

Nesse sentido, a questão que emerge é se o cooperativismo de Mondragón está preparado para estes desafios, ou se, a exemplo da racionalidade instrumental e econômica ${ }^{2}$ que opera na economia de mercado globalizado, necessita de processo de revitalização e renovação de suas motivações sociais e humanistas, conectado aos novos desafios da época atual.

\footnotetext{
${ }^{1}$ Nesta década foi criado o projeto educativo, reconhecido hoje pela Faculdade Politécnica de Engenharia, que por sua vez, transformou-se na Universidade de Mondragón, na década de 1950 .

${ }^{2}$ Veja FERNANDES (2008).
} 
Este desafio porta a exigência de que ideais socioeconômicos que nortearam o surgimento e a evolução do cooperativismo de Mondragón não podem mais estar desconectados ou negligenciar os limites impostos pelos sistemas naturais. Portanto, remete a uma transformação dos ideais socioeconômicos em ideais socioambientais, norteados pelo paradigma da sustentabilidade, em substituição ao paradigma de crescimento econômico como solução de todos os problemas. O objetivo deste artigo, portanto, é resgatar os princípios considerados pelo idealizador José María Arizmendiarrieta que podem subsidiar as adaptações necessárias ao enfoque socioeconômico, transcritos nos 10 princípios da MCC, bem como as suas implicações ideológicas e práticas, considerando o paradigma da sustentabilidade, por meio do enfoque da ecossocioeconomia.

Esta pesquisa valeu-se de observação participativa realizada pelo primeiro autor, com duração de três meses, na qual se vivenciou a experiência de Mondragón a partir de entrevistas e visitas. Dois outros autores, cooperados de Mondragón, complementaram os dados primários. A descrição e a análise da experiência também se basearam em dados secundários.

\section{A ética e a ascese do cooperativismo de Mondragón}

É importante mencionar que o marco histórico de referência do fundador do cooperativismo de Mondragón é a sociedade industrial da segunda metade do século XX. Seu ponto de partida era a crítica ao liberalismo. Crítica que também se estende ao socialismo real e que o conduz ao personalismo de origem francês. Preocupado com a degradação dos fundamentos morais, Arizmendiarrieta ataca o individualismo imperante, o afã pelo lucro e a supremacia do mercado. Estes são os elementos básicos de uma crítica social de fundo.

Mais recentemente, nos últimos anos, a experiência de cooperativismo de Mondragón vem passando por um período de perda da radicalidade em relação ao verdadeiro espírito cooperativo a partir do qual foi iniciado.

Perry Anderson (1986, p. 132) afirmava que o marxismo busca "agentes subjetivos, capazes de estratégias efetivas para desmontar estruturas objetivas". Na verdade, é o que normalmente buscam os projetos de transformação social. No caso do cooperativismo de Mondragón, isto não é diferente. Constrói-se uma subjetividade coletiva que de forma efetiva transforma a estrutura organizativa do modo capitalista, criando uma experiência de autogestão na qual se inclui a classe trabalhadora.

A formação deste agente subjetivo é algo bastante complexo (AZKARRAGA, 2007). No caso de Mondragón, esta formação está ligada a pelo menos quatro aspectos culturais importantes:

a) cultura rural basca, origem de toda a primeira geração cooperativista, inclusive Arizmendiarrieta. O traço cultural da tradição basca, mitologia com características matriarcal, naturalista e comunitária, diferente do caráter racionalista das mitologias patriarcais, cujo predomínio era do individualismo;

b) poderosa cultura industrial já existente antes do surgimento do cooperativismo de Mondragón no Valle-Madre;

c) cosmovisão e a ideologia trabalhista próprias de toda uma geração e da sociedade industrial moderna, que se coadunam com a identidade coletiva basca, na medida em que o basco se define socialmente como um bom trabalhador; e

d) por fim, a mensagem social do cristianismo, por meio da Doutrina Social da Igreja. Uma vez que a sociedade basca do século XX foi uma sociedade profundamente religiosa, seu processo de secularização se deu somente no final do século passado.

Além dos fundamentos culturais descritos, que sedimentaram a base de uma subjetividade peculiar, a conformação de tal agente subjetivo se deu também por meio de um longo processo educativo de caráter integral, liderado por Arizmendiarrieta, cujos conteúdos foram: educação espiritual, considerando a matriz católica; sociológica; técnica; e educação para o compromisso social prático. Antes da criação da primeira cooperativa e do movimento cooperativista de Mondragón, os primeiros cooperados passaram por aproximadamente quinze anos de formação, visando construir a densidade subjetiva necessária.

Sem a pretensão de fazer uma leitura idealizada e romântica do passado, pode-se afirmar que na sua gênese, e em boa parte da sua evolução posterior, o cooperativismo de Mondragón significou para muitos dos que nele participaram uma causa com status de redenção. Significava participar na redenção da humanidade, em troca de uma boa dose de sacrifício quotidiano, austeridade, disciplina e renúncia aos próprios interesses individuais. Nesse sentido, a base valorativa da experiência de Mondragón, bem como seus conteúdos, constituem-se numa ética cooperativista, que num paralelo com a ética protestante, desvelada por Max 
Weber, fundamenta e justifica a ascese cooperativista de Arizmendiarrieta, cuja racionalidade tem o mesmo caráter instrumental da ética protestante, mesmo que as finalidades sejam outras. Em vez de buscar a salvação eterna após a morte, se busca a redenção aqui mesmo na terra, sob signos de liberdade e emancipação, sobretudo a partir do trabalho.

Em um contexto de pós-guerra, no qual predominava a miséria material e moral, a experiência de Mondragón desponta como uma experiência de desenvolvimento territorial, seguindo a conceituação desenhada por Berger $(1979$, p. 30), na qual desenvolvimento não constitui apenas atingir metas a partir de ações racionais na esfera da economia empresarial; constituiu-se também, em um nível mais profundo, o centro das esperanças e expectativas de redenção, ou, em termos menos religiosos, expectativas de libertação e emancipação. O paradigma do progresso e o mito do crescimento econômico ilimitado como principal solução para os problemas humanos estão no cerne da experiência cooperativa de Mondragón.

No contexto da sua fundação, foi a motivação religiosa que sustentou este compromisso vital e mobilizou boa parte das energias cooperativas. Tratava-se de fazer frente ao principal conflito da sociedade industrial, o conflito capital-trabalho, num contexto internacional, marcado pela forte divisão entre os grandes sistemas econômicos, sociais e culturais. Isto deveria ser feito pela via traçada pela doutrina social católica, que concerne harmonização dos dois elementos, capital e trabalho, em um único sujeito, através da via cooperativa, com especial atenção ao fator trabalho. Na perspectiva cristã, o cooperativismo impregnou todo um modo de vida em muitos dos atores da primeira geração. Era uma ascese, capaz de sustentar um projeto de vida comprometido com a sociedade do seu tempo, baseado em valores de entrega, justiça social, igualdade de oportunidades, autocontrole material e pragmatismo. $\mathrm{O}$ ideário cooperativista tornou-se um modelo de conduta de vida.

Assim, o cooperativismo de Mondragón foi constituído sobre três principais bases que sustentaram a identidade das pessoas na primeira modernidade: ascese religiosa, luta de classes e nacionalismo. $\mathrm{O}$ cristianismo, o nacionalismo e a ascensão social, e todos juntos com o pragmatismo empresarial, o paradigma do progresso e do desenvolvimento, constituem a constelação ideológica e a base deste cooperativismo. Esta constelação ideológica constituiu a base de legitimação e a bússola de orientação, dando sentido às ações de seus protagonistas. O peso específico de cada um dos impulsos mencionados foi distinto ao longo da história, em função da evolução ideológica da própria sociedade em seu conjunto. A década de 1990, porém, foi a década da expansão internacional de boa parte das cooperativas industriais, do seu processo de globalização, em que as representações ideológicas com esquemas de valores bem definidos se viram seriamente debilitadas. Houve um deslocamento gradual em direção a algo ainda pouco compreendido, mas que descende da globalização econômica e cultural, sustentada principalmente pelo alto desenvolvimento dos meios de comunicação e locomoção, possibilitando um amplo processo de trocas, principalmente culturais.

Ao mesmo tempo, a noção de desenvolvimento vem sofrendo profunda, e talvez tardia, transformação na sociedade global. O desenvolvimento, baseado no crescimento econômico, considerado em muitas sociedades como o centro das esperanças e expectativas de redenção, para usar termos do cooperativismo de Mondragón, começa a ser questionado em vista da crise ambiental.

\section{A perspectiva da ecossocioeconomia das organizações}

O termo ecossocioeconomia surge a partir da obra do economista e ecólogo Karl William Kapp (1963). O prefixo "eco" (oikos = casa) se refere à ecologia e reforça o que o segundo prefixo "eco" já deveria significar na ação social, porém teve seu sentido deslocado ao longo da história para o que Aristóteles definiu como crematística, quando na sua análise denunciava que a economia perdia o seu sentido mais nobre, aquele de suprir as necessidades, para adquirir significado de busca de riqueza.

A ecossocioeconomia está imbricada na discussão sobre o ecodesenvolvimento, surgido na década de 1970 e renomeado de desenvolvimento sustentável nos anos de 1980. O ecodesenvolvimento foi apontado como um paradigma sistêmico, compreendendo princípios da ecologia profunda como proposta de repensar os atuais estilos de vida, da socioeconomia no sentido de ponderar as consequências sociais na ação econômica, da economia ecológica, quando esta calcula custos ambientais na ação econômica, e da ecologia humana, principalmente a premissa da inseparabilidade dos sistemas sociais e ecológicos. Além disso, Conforme Sampaio (2010), merece destaque a questão democrática, principalmente por meio de processos participativos, viabilizados por instrumentos como o planejamento participativo. 
Vale destacar que o termo socioeconomia ${ }^{3}$, predominantemente usado na Europa, equivale à economia social, mas compreende outras concepções, resguardando a singularidade de cada uma, como é o caso da socioeconomia solidária (LISBOA, 2005), economia descalça (MAX-NEEF et al., 1986), economia popular solidária (RAZETO, 1997) e economia solidária (SINGER, 2002). A socioeconomia versa sobre problemas microeconômicos com soluções de base territorial, relacionados a transformações sociais e modos de vida (SANTOS et al., 2002; DOUROJEANNI, 1996), baseando-se na capacidade endógena e na emancipação (empowerment) das comunidades locais (SACHS 1986a, 1986b). Entretanto, sob a perspectiva socioambiental, a socioeconomia apresenta limitações tanto teóricas como práticas, como bem exemplificam experiências como o cooperativismo de Mondragón. Torna-se necessário, assim, repensar os seus fundamentos para que seja possível repensar também os processos de gestão.

Cabe pontuar que enquanto o ecodesenvolvimento privilegia o enfoque epistemológico-teórico, a ecossocioeconomia enfatiza o enfoque metodológico-empírico. A ecossocioeconomia ocorre no mundo da vida, nas comunidades, nos povoados, nas organizações, onde os problemas e as soluções acontecem e raramente são devidamente qualificados (SAMPAIO, 2010). Trata-se de uma teoria pensada, partindo das experimentações e da complexidade do cotidiano (SACHS, 1986a).

$\mathrm{O}$ enfoque ecossocioeconômico pode ser aplicado também no contexto organizacional, que poderia ser denominado ecossocioeconomia das organizações. Trata-se de pensar a viabilidade interorganizacional considerando o espaço extraorganizacional e o território, além de contemplar a chamada extrarracionalidade nos processos de tomada de decisão aos grupos organizados (associações e cooperativas) ou quase organizados (movimentos sociais e grupos produtivos).

A ecossocioeconomia das organizações privilegia os estudos que possibilitam as viabilidades macro (interorganizacional) e microeconômica (organizacional) de grupos organizados ou quase organizados e articulados, chamados de empreendimentos compartilhados, e sugere a eminência de uma ação extraorganizacional, isto é, o agente organizacional relevando os impactos de sua ação sobre o entorno territorial. Isto pode ocorrer por meio de acordos institucionais, pensados como acordos sociopolíticos e socioprodutivos de base comunitária, de modo que gerem capital social. Neste caso, quando a ênfase for sociopolítica, chama-se de arranjo institucional, enquanto quando a ênfase for socioeconômica, a denominação é arranjo produtivo local.

A construção de tais arranjos depende da identificação dos representantes das organizações que irão compor os acordos, reunir e estimular as bases para pensar três diferentes ações: interorganizacionais, extraorganizacionais e extrarracionais (SAMPAIO, 2010, p. 13). A interorganização não pode ser legítima senão quando se origina de um consentimento necessariamente consensuado. Este entendimento mútuo sobrepõe-se às ações voltadas ao sucesso, às vezes chamadas equivocadamente de estratégicas, materializadas em sujeitos oportunistas para influenciar outros (HABERMAS, 1990).

A participação interorganizacional deve, então, girar em torno do espaço mediado entre o interesse público e o privado, que é uma ação coletiva, operando sobre as bases da intersubjetividade e do entendimento genérico pela linguagem trivial do cotidiano, em distinção dos símbolos específicos vigentes nas diferentes instituições (entendidas como organizações). O espaço público representa o nível onde se dá esse confronto de opiniões que disputam o recurso escasso da tematização e da consequente atenção dos tomadores de decisão. As esferas do Estado, mercado e sociedade civil, mesmo que ainda possuam ambiguidades quanto ao caráter público do problema, ora se complementando, ora se interpondo, devem ser vistas como potenciais criadores que enriquecem o processo de negociação. Pois são elas (as esferas) que legitimam os processos participativos - como são os arranjos institucionais e produtivos -e que, consequentemente, possibilitam, no bojo da discussão, o surgimento de questões estratégicas negociadas, o que, neste caso, é necessariamente diferente da soma destas esferas (COHEN; ARATO, 1992; COSTA, 1994).

O conceito extraorganizacional está atrelado ao de interorganizacional. Quando se governa uma interorganização presume-se que, além dos critérios de eficiência

\footnotetext{
${ }^{3}$ A origem da socioeconomia remonta aos anos oitenta do século passado, quando um grupo de notáveis sociólogos e economistas fundaram a Sociedade Mundial de Socioeconomia (SASE), em Harvard, em 1989. Entre seus membros figuram cientistas de porte, como K. Boulding, A. Hirschman, J. Galbraith, A. Sen, H. Simon, R. Boyer, P. Bourdieu, N. Smelser, L. Thurow, R. Solow; além do seu promotor maior, o sociólogo norte-americano Amitai Etzioni (GUERRA, 2007, p. 1).
} 
(é medida através dos processos de produção que, no seu conjunto, determinam o grau de produtividade) e eficácia (é verificada através dos resultados desses processos de produção, que determinam, por sua vez, o grau de competitividade), atrelados à gestão organizacional, deve-se privilegiar o critério efetividade, isto é, relevar a gestão de risco socioambiental quanto ao território. O conceito de território deve estar distanciado da sua subversão ou sua subordinação aos fluxos meramente econômicos, recompondo-se e reconceituando-se como um movimento de elementos, entre eles, sociais, geográficos e naturais; e a preocupação não está na definição de seus limites, mas nos entrelaçamentos que o compõem. Não há, então, como estudar o território sem fazê-lo correlativamente, em duplo sentido, com os demais contextos: local, microrregional, regional, nacional e internacional. Entretanto, o território possui especificidades que não devem ser tomadas como mero reflexo destes demais contextos. Sugere-se, então, que num cenário de gestão interorganizacional ou arranjo institucional, o conjunto de organizações que o compõem deve refletir não apenas a microcomplexidade do território, mas também a macrocomplexidade dos demais espaços (FISCHER, 1993; SANTOS, 1994; LÉVY, 1998).

Operacionalizando estes dois princípios da ecossocioeconomia nas organizações, sugere-se que a governança interorganizacional deve ser conduzida pautada por critérios extraorganizacionais, no sentido de incorporar demandas socioambientais oriundas do território ao qual a interorganização está instalada; critérios onde a racionalidade seja conduzida pelo cálculo de consequências societárias, privilegiando as dimensões socioeconomicoambientais para poder corrigir os equívocos provocados por um modelo de gestão que privilegia apenas ajuizamentos intraorganizacionais (para dentro da organização), baseado numa racionalidade econômica de cálculo de consequências apenas organizacional (SAMPAIO, 2000; 2004). Diante da impregnação do termo racionalidade com critérios econômicos, resgata-se o termo extrarracionalidade, que pode ser considerado como uma pré-racionalidade, baseado em uma dimensão tácita, ou seja, ainda pouco visível, do conhecimento contido nas organizações, nos territórios, onde os problemas realmente acontecem e suas soluções também (FERNANDES; SAMPAIO, 2006).

\section{Princípios da socioeconomia do cooperativismo de Mondragón como ancoragem para gestão socioambiental}

Não obstante a aparente visão antropocêntrica de Arizmendiarrieta, a análise mais apurada do seu pensamento revela alguns pontos de alavancagem para uma gestão socioambiental. Pontos estes que revelam a existência de uma compreensão e preocupação em conter os excessos do homem e da sociedade sobre o meio ambiente natural. Limites sem os quais se coloca em risco o próprio equilíbrio socioeconômico almejado pelo cooperativismo e que, no contexto atual, se mostram especialmente relevantes.

Responsabilidade ambiental: Arizmendiarrieta inclui, entre os imperativos da maturidade, a responsabilidade ambiental, advertindo sobre o risco da obstinação pelo desenvolvimento desmedido e dilapidador dos recursos naturais.

Relativismo do desenvolvimento econômico: para o fundador do cooperativismo de Mondragón, o último fundamento e fim de todo e qualquer ser humano é a dignidade da pessoa. Consequentemente, o desenvolvimento econômico só é um meio a serviço do bem-estar humano. O mal-estar geral que o autor observa nas sociedades industriais é devido ao forte desajuste entre o ritmo das mudanças materiais e as transformações culturais. "O mal vem de um desenvolvimento demasiado rápido das ciências da matéria em relação às ciências humanas" (AZURMENDI, 1992, p. 343).

Austeridade e frugalidade como caminho de liberdade: tanto em se tratando da produção como do consumo, Arizmendiarrieta, alinhado com a Doutrina Social da Igreja, defende o autocontrole e a economia, no sentido de poupança, cujo fundamento não reside apenas em critérios econômicos, mas também éticos, pedagógicos e políticos. O significado de solidariedade exige austeridade e compromisso. "Somos capazes de viver com menos viagens, roupas e equipamentos que a maioria que nos rodeia, sem nos sentirmos, por isso menos pessoas, mas ao contrário, devemos nos orgulhar de poder dar testemunho à maioria que não está disposta a isto" (AZURMENDI, 1992, p. 307).

Crítica ao consumismo: intimamente ligado aos valores de austeridade e frugalidade, Arizmendiarrieta despreza a sociedade de consumo, porque é um fator de acomodação, numa sociedade em que "sentir-se satisfeito é um luxo intolerável” (AZURMENDI, 1992, p. 307). Além 
disso, como consequência de sua origem produtivista, valoriza mais os bens úteis à reprodução social do que ao consumo final. Esta crítica tem como base tanto critérios políticos como morais:

Olhando nossos lares, cheios de objetos supérfluos, as estradas estreitas e inadequadas para o nosso transporte, os estacionamentos mais caros e extensos que os ocupados por muitos navios de carga de nosso país, o ir e vir sem muita necessidade que consomem os poucos recursos energéticos que poderiam ser úteis a outras atividades mais indispensáveis, é possível falar honestamente de racionalidade, solidariedade, de bem comum, de gestão social e participativa, de correta utilização dos recursos ilimitados? (AZURMENDI, 1992, p. 307).

Solidariedade intergeracional: a solidariedade, que segundo Arizmendiarrieta deve se estender a todos os campos da vida pública em sociedade, também implica solidariedade com o futuro. Cada geração tem a responsabilidade de conservar para a geração vindoura os bens comunitários compartilhados.

Um presente, por melhor que seja, nega o futuro, na medida em que traz consigo uma validade. Não podemos parar nem resistir ao futuro em um período em que o fenômeno mais significativo é a aceleração e a mudança, sob pena de agir insensatamente. (AZURMENDI, 1992, p. 308).

Compromisso com a comunidade: a comunidade, na concepção do fundador do cooperativismo de Mondragón, é ativa em todo momento e é responsável pela potencialização e promoção do individuo. A cooperativa, como comunidade de trabalho, busca antes de tudo um fim social.

Já não é legitimável uma abordagem individualista, não solidária, que visa [a] resultados e benefícios, sejam individuais ou da empresa, ignorando a promoção comunitária simultânea. Onde houve comunidades fortes, entendidas como aquelas nas quais existem opções de trabalho, de educação, de saúde e de lazer, de forma ampla e indiscriminadas, onde não há lugar para miséria de ninguém. (AZURMENDI, 1992, p. 309).
Ancoragem territorial: a ideia de desenvolvimento de Arizmendiarrieta é fundada na autonomia do individuo, da comunidade e realça o valor do local. Na verdade, os dois traços fundamentais do conceito de autogestão são o enraizamento territorial e a vocação de integralidade.

\begin{abstract}
Nós cooperativistas devemos nos sentir comprometidos para demonstrar as possibilidades da autogestão, isto é, de homens que resolvem livremente e por si mesmos problemas difíceis, demonstrando sua elevada visão e projeção (AZURMENDI, 1992, p. 671).
\end{abstract}

Ou seja, assumir e exercer a cidadania com suas próprias capacidades de transformação, sem esperar ou requerer a intervenção de terceiros, seja de agentes públicos ou privados, deflagrando ações de baixo para cima e do local para o global.

Assim, considerando a gestão socioambiental a partir destes pontos de ancoragem extraídos do pensamento de Arizmendiarrieta, a experiência de Mondragón tem um desenho claro, que, se por um lado preserva certo antropocentrismo, por outro traz lições bastante úteis à crise ambiental atual, quando transforma austeridade, frugalidade, crítica ao consumismo e ancoragem territorial em cidadania, responsabilidade ambiental, compromisso com a comunidade e solidariedade intergeracional. Este sistema de valores é, com efeito, a base de um modelo de gestão socioeconômico em que se evidencia a transversalidade fundamental da dimensão ambiental. Além dos pontos mencionados, o cooperativismo mondragonês está fundamentado também em um conjunto de princípios e a discussão que se segue é como estes princípios podem contribuir para uma gestão socioambiental a partir da análise sob o enfoque da ecossocioeconomia.

\section{Dez princípios do Cooperativismo de Mondragón à luz da socioeconomia}

Como já assinalado, o cooperativismo de Mondragón é fundamentado em 10 princípios que norteiam a sua ascese. Da mesma forma, mencionou-se que esta experiência, embora emblemática, encontra-se em crise e necessita ser atualizada na sua prática. Dentre as atualizações necessárias, merece destaque a relação com o meio ambiente, transcendendo a ascese puramente antropocêntrica. Nos pontos 
de ancoragem vistos anteriormente, a partir do estudo de Azurmendi (1992), uma das autoridades sobre a experiência de Mondragón, sobretudo de seu fundador, Arizmendiarrieta, é possível identificar inúmeras oportunidades rumo a uma gestão socioambiental, a partir da experiência do cooperativismo mondragonês.

Indo mais a fundo, na própria fonte inspiradora do cooperativismo encontra-se um conjunto de princípios já estabelecidos pela Mondragón Corporação Cooperativa, com os quais se sugere, à luz do enfoque ecossocioeconômico, um conjunto de adaptações, visando transformar a prática socioeconômica em uma prática socioambiental e econômica.

\section{$\underline{\text { Livre adesão }}$}

La experiencia cooperativa de Mondragon se declara abierta a todos los hombres y mujeres que acepten estos Principios Básicos y acrediten idoneidad profesional para los puestos de trabajo que pudieran existir. No existirá, por tanto, para la adscripción a la experiencia, discriminación alguna por motivos religiosos, políticos, étnicos o de sexo. Solamente será exigible el respeto a los postulados de su constitución interna. La libre adhesión constituirá el principio orientador de la actuación y relación interpersonal en el desarrollo cooperativo. (ALTUNA, 2008, p. 266)

Sob a perspectiva da ecossocioeconomia, a livre adesão preconizada pelo cooperativismo de Mondragón deve ser atualizada, transcendendo os limites da ascese religiosa que the era predominante e adquirindo significado de emancipação sociopolítica, como preconizado na noção aristotélica de razão e que é resgatada por Ramos (1989), quando discute as possibilidades de uma racionalidade mais substantiva na vida associada. Na vida em sociedade, a liberdade ocorre sempre dentro de certos limites e, nesse sentido, é importante que a adesão ocorra como resultado de emancipação política, em sentido aristotélico, como resultado de educação e não de catequese, sem, no entanto, prescindir dos valores nos quais se acredita, inclusive religiosos.

\section{Organização democrática}

La experiencia cooperativa de Mondragon proclama la igualdad básica de los socios trabajadores en lo que respecta a sus derechos a ser, poseer y conocer, lo que implica la aceptación de una organización democrática de la empresa, concretada en: a) La soberanía de la Asamblea General, compuesta por la totalidad de los socios, que se ejercita según la práctica de "una persona, un voto".

b) La elección democrática de los órganos de gobierno, y en concreto del Consejo Rector, responsable de su gestión ante la Asamblea General.

c) La colaboración con los órganos directivos designados para gestionar la sociedad por delegación de toda la comunidad, que gozarán de las atribuciones suficientes para desarrollar eficazmente sufunción en beneficio común. (ALTUNA, 2008, p. 268)

A democracia na gestão organizacional é um dos avanços da experiência mondragonesa em relação às empresas capitalistas. Todavia, como apontam Mantovaneli Jr. e Sampaio (2006), os processos democráticos não garantem sustentabilidade ambiental. Um processo de gestão pode ser considerado com maior ou menor sustentabilidade administrativa e política se for capaz de institucionalizar, avaliar e ajustar seus processos à luz das demandas efetivas da sociedade, considerando também o contexto ambiental mundial e intergeracional. Do ponto de vista do paradigma da sustentabilidade, nada mais natural que o exercício da democracia, pois se trata de um bem coletivo de uso público. Nesse contexto, em processos de gestão, o exercício da democracia vem ocorrendo principalmente por meio de instrumentos como planejamento e gestão participativos, arranjos socioprodutivos e políticos de base comunitária e territorial, conselhos gestores, dentre outros.

\section{Soberania do trabalho}

La experiencia cooperativa de Mondragon considera que el trabajo es el principal factor transformador de la naturaleza, de la sociedad y del propio ser humano y, por consiguiente:

a) Renuncia a la contratación sistemática de trabajadores asalariados.

b) Adjudica al trabajo plena soberanía en la organización de la empresa cooperativa.

c) Considera al trabajo acreedor esencial en la distribución de la riqueza producida.

d) Manifiesta su voluntad de ampliar las opciones de trabajo a todos los miembros de la sociedad. (ALTUNA, 2008, p. 271)

A soberania do trabalho é desejada, porém deve ser pensada partindo de delimitações socioambientais. Um trabalho apenas fundamentado na visão antropocêntrica sugere uma relação assimétrica (senão dominadora) entre 
os homens e entre eles e a natureza, ao invés de uma relação de sinergia dentro dos parâmetros da racionalidade socioambiental. O trabalho deve ser pensado como forma de emancipação, proporcionando a recriação não apenas do próprio trabalhador no âmbito da empresa, mas também como indivíduo e cidadão fora dela, como já havia sugerido Arizmendiarrieta. Entretanto, os processos de mecanização, típicos da indústria, setor vital dentro da Corporação Mondragonesa, limitam a cooperação e a participação e têm como consequência a desmobilização, que é vital quando se tratam de atividades não remuneradas, como a participação institucional na própria cooperativa, por meio de assembleias, comissões e conselhos, assim como em atividades comunitárias. Não há dúvida que isto seja um dos principais desafios da experiência mondragonesa.

\section{Instrumentalização e subordinação do capital}

La experiencia cooperativa de Mondragon considera al factor Capital como un instrumento, subordinado al trabajo, necesario para el desarrollo empresarial, y acreedor por tanto: a) A una remuneración:

- Justa, en relación a los esfuerzos que implica su ahorro. - Adecuada, para propiciar la adscripción de los recursos necesarios

- Limitada en su cuantía, mediante la correspondiente regulación.

- No directamente vinculada a los resultados obtenidos.

b) A una disponibilidad subordinada a la continuidad y desarrollo de la cooperativa, que no impida una real aplicación del principio de libre adhesión. (ALTUNA, 2008, p. 273)

O caráter instrumental e a subordinação do capital também são avanços da experiência mondragonesa frente às empresas capitalistas. Contudo, o trabalho eminentemente humano deve ter caráter intimamente relacionado com os pressupostos mínimos dos sistemas ambientais: não retirar dos ecossistemas mais que sua capacidade de regeneração e não lançar aos ecossistemas mais que a sua capacidade de absorção. A crise do paradigma capitalista e do próprio cooperativismo - quando alijado do enfoque socioambiental - está baseada no fato de esgotar suas próprias fontes de riqueza e de sustentabilidade, o trabalhador e os recursos naturais (FERNANDES; SAMPAIO, 2008).

\section{Gestão participativa}

La experiencia cooperativa de Mondragon estima que el carácter democrático de la Cooperativa no se agota en su vertiente societaria, sino que implica un desarrollo progresivo de la autogestión y consecuentemente de la participación de los socios en el ámbito de la gestión empresarial, lo que, a su vez, requiere:

a) El desarrollo de los mecanismos y cauces de participación adecuados.

b) La transparencia informativa en relación a la evolución de las variables básicas de gestión de la Cooperativa.

c) La práctica de métodos de consulta y negociación con los socios trabajadores y sus representantes sociales en las decisiones económicas, organizativas y laborales que les conciernan o afecten.

d) La aplicación sistemática de planes de formación social y profesional de los socios.

e) El establecimiento de la promoción interna como vía básica para la cobertura de los puestos con mayor responsabilidad profesional. (ALTUNA, 2008, p. 274)

A busca por um modelo participativo de gestão endógeno, ao invés de um modelo vindo de fora, é característica da experiência mondragonesa. Entretanto, permanece o desafio de um estilo de gestão participativa cooperativa com identidade territorial, que gere o sentimento de pertencimento ao território e, ao mesmo tempo, ao planeta. Uma identidade cooperativa que seja ecossocioeconômica no plano político-institucional, na gestão empresarial e no plano técnico-operacional. Seria imprescindível que tal estilo iniciasse desde o conselho diretor, passando pela gerência, chegando aos trabalhadores tanto sociocooperativistas assim como não sociocooperativistas (uma discussão, todavia, inacabada). Uma participação que no contexto de trabalho dinamizasse outras formas de participação, sem necessariamente estar relacionada aos órgãos de governo.

Levar em conta que a participação qualifica melhor a tomada de decisão, sem, no entanto, correr riscos de superdemocratização, levando ao assembleísmo, mas que os conflitos de ideias e de interesses deem significado ao trabalho, amenizando o automatismo das tarefas ordinárias, assim como a tendência a se produzir um trabalhador que, alienado no seu trabalho, também o será no consumo (FERNANDES, 2008). Nesta perspectiva, a racionalidade que motiva as pessoas ao trabalho deve conter três componentes gerais, além da lógica instrumental: desenvolvimento pessoal, ou seja, equilíbrio entre trabalho produtivo e reprodutivo, evitando o automatismo alienado; pertencimento a um grupo, a uma comunidade, a um projeto compartilhado; e, sobretudo, sentir-se coautor de uma causa ou compromisso, neste caso socioambiental (ALTUNA, 2008). 
Solidariedade distributiva

La experiencia cooperativa de Mondragon proclama la retribución suficiente y solidaria como un principio básico de su gestión, expresada en los términos de:

a) Suficiente, acorde con las posibilidades reales de la Cooperativa.

b) Solidaria, materializada:

- En el ámbito interno: en la existencia de un marco solidario de retribuciones al trabajo.

- En el ámbito externo: en el criterio de que la remuneración media interna sea homologable con la de los trabajadores asalariados de su entorno sectorial, y en su caso, territorial, salvo manifiesta insuficiencia de la política salarial en el mismo.

- A nivel de Mondragon, en la existencia de un marco laboral solidario tanto en cuanto a la retribución del trabajo como en cuanto al horario de trabajo anual para todas las cooperativas pertenecientes al mismo. (ALTUNA, 2008, p. 276-277)

A solidariedade distributiva é uma das lições e ganhos da experiência mondragonesa que supera as do modelo de produção puramente capitalista, evidenciando as possibilidades reais das cooperativas e materializando a solidariedade nos âmbitos interno e externo. Sob o enfoque da ecossocioeconomia, falta somente a solidariedade intergeracional e planetária. Nesse sentido, como sugestão, poder-se-ia adotar o instrumento gerencial balanced scorecard adaptado por Sampaio (2000), no sentido de avaliar indicadores extraorganizacionais, entre estes, intergeracionais e planetários nos processos de gestão organizacional e interorganizacional.

\section{$\underline{\text { Intercooperação }}$}

La experiencia cooperativa de Mondragon considera que, como aplicación concreta de solidaridad y requisito de eficacia empresarial, el principio de Intercooperación debe manifestarse:

a) Entre cooperativas individualmente consideradas, a través de la constitución de Agrupaciones tendentes a la creación de un régimen socio-laboral homogéneo, incluida la reconversión común de resultados, la regulación de transferencias de socios trabajadores y la búsqueda de las sinergias potenciales derivadas de la dimensión conjunta. b) Entre agrupaciones, mediante la constitución y gestión democrática, en beneficio común, de entidades y órganos de supraestructura. c) Entre la experiencia cooperativa de Mondragon y demás organizaciones cooperativas vascas, con el fin de potenciar el Movimiento Cooperativo Vasco.

d) Con otros movimientos cooperativos del Estado, Europeos y del resto del mundo, realizando acuerdos y estableciendo órganos conjuntos dirigidos a propiciar el desarrollo común. (p. 279)

A experiência mondragonesa de intercooperativismo pode ser vista através de algumas chaves de leitura: uma holding cooperativa, Mondragón Corporação Cooperativa (MCC), que assessora as iniciativas de desenvolvimento de negócios e presta serviços técnicos, jurídicos e financeiros; um congresso cooperativo que discute, de tempos em tempos, a visão institucional da experiência; um banco de investimento, bem como um sistema de assistência e provisão social próprio; cooperativas que funcionam, porém pensadas a partir de um desenvolvimento territorial, com encadeamentos muito estreitos, verticais e horizontais; fundo intercorporativo, com finalidade primordial de garantir uma divisão mais homogênea e solidária dos benefícios para a realização de projetos individuais e coletivos das cooperativas e de seu entorno; uma universidade, centros de Inovação e Desenvolvimento (I+D) intercooperativos.

O conceito de intercooperação torna denso o conceito interorganizacional, a partir do termo clusters. O conceito de clusters vem se limitando, dentro de um tema interorganizacional, como estrutura de arranjos socioprodutivos (não tanto socioeconômicos e muito menos socioambientais) de base territorial e não como governança inter e intraorganizacionalmente, como bem demonstra a experiência mondragonesa. A intercooperação se apoia nas vantagens econômico-empresariais da associação de cooperativas e permite estabelecer as bases para potencializar os valores cooperativos e, concretamente, o compromisso das cooperativas com a sociedade (ALTUNA, 2008; ALTUNA; GRELLIER; URTEAGA, 2008).

\section{Transformação social}

La experiencia cooperativa de Mondragon manifiesta su voluntad de transformación social solidaria com la de otros pueblos, a través de su actuación en el marco de Euskal Herria en un proceso de expansión que colabore a su reconstrucción económica y social y a la edificación de una sociedad vasca más libre, justa y solidaria, mediante: a) La reinversión de una proporción mayoritaria de los Excedentes Netos obtenidos, destinando una proporción significativa a los Fondos de carácter comunitarios, que 
permita la creación de nuevos puestos de trabajo en régimen cooperativo.

b) El apoyo a iniciativas de desarrollo comunitario, mediante la aplicación del Fondo de Obras Sociales.

c) Una política de Seguridad Social coherente con el sistema cooperativo, basado en la solidaridad y responsabilidad.

d) La cooperación con otras instituciones vascas de carácter económico y social, y especialmente las promovidas por la clase trabajadora vasca.

e) La colaboración en la revitalización del euskara como lengua nacional y, en general, de los elementos característicos de la cultura vasca. (ALTUNA, 2008, p. 281-282)

Com já dito anteriormente, mais que em transformação social deve-se pensar em termos socioambientais. Mondragón foi protagonista de uma experiência revolucionária em seu tempo, a chamada economia social. Todavia, deve continuar inovando, considerando os novos tempos e a necessidade de uma ecossocioeconomia. É preciso resgatar os conhecimentos tradicionais que constituem o marco de Euskal Herria ${ }^{4}$, suas histórias e contos, seus locais sagrados, suas tecnologias apropriadas, a subjetividade coletiva, a paisagem que constitui ou serve para recarregar as energias, ou seja, restabelecer a relação assimétrica entre homem e natureza.

\section{Caráter universal}

La experiencia cooperativa de Mondragón, como expresión de su vocación universal, proclama su solidaridad con todos los que laboran por la democracia económica en el ámbito de la "Economía social", haciendo suyos los objetivos de Paz, Justicia y Desarrollo, propios del Cooperativismo Internacional. (ALTUNA, 2008, p. 284)

O caráter universal deve ser assumido como responsabilidade socioambiental planetária, como bem fazem atualmente as iniciativas da Fundação Mundukide. A experiência mondragonesa não pode ser reduzida a um mero caso empresarial. É necessário fazer da experiência um case que possibilite expandir uma racionalidade (através de um processo educativo) mais substantiva no mundo dos negócios e, oxalá, que seja reinventada a partir da racionalidade ambiental. Ela deve servir de exemplo de um paradigma que é possível (e não perfeito) e que não seja necessariamente outro paradigma hegemônico. É preciso aprender a conviver com lógicas distintas, mesmo que tal não seja fácil.

\section{Educação}

La experiencia cooperativa de Mondragón manifiesta que para promover la implantación de los anterioresPrincipios es fundamental la dedicación de suficientes recursos humanos y económicos a la Educación, en sus diversas vertientes: a) Cooperativa, del conjunto de los socios y en especial de los elegidos para los órganos sociales.

b) Profesional, en especial de los socios designados para los órganos directivos.

c) En general, de la juventud, propiciando el surgimiento de hombres y mujeres cooperadores, capaces de consolidar y desarrollar la experiencia en el futuro. (ALTUNA, 2008, p. 286)

Considerar os princípios do cooperativismo mondragonês à luz do enfoque ecossocioeconomico significa resgatar não só o caráter educacional e emancipatório preconizado pelo seu fundador, como também evidenciar outros elementos fundamentais que levem em conta os novos desafios em tempos de aquecimento global. Portanto, quando se considera a educação como o primeiro e o principal princípio, trata-se de uma educação que se desloque da racionalidade antropocêntrica, como a que fundamentou prioritariamente a prática do cooperativismo de Mondragón, para uma racionalidade socioambiental na qual haja a compreensão de que os sistemas são integrados, premissa a partir da qual os processos decisórios devem ser norteados. Embora estas premissas estivessem presentes na concepção cooperativista de Arizmendiarrieta, nem sempre foi considerada na sua prática, principalmente nos anos recentes.

Embora a racionalidade socioambiental, assim como a racionalidade substantiva que norteia a economia social, deva ser provida de certa instrumentalidade para ser compatível com a economia formal de mercado predominante no mundo contemporâneo, esta instrumentalidade não deve mirrar a educação, principalmente no que concerne à capacidade de compreensão, cegando os tomadores de decisão para compreensão da capacidade de carga do planeta. É preciso que estejam intrínsecos nos processos de tomada de decisão a consciência e o conhecimento de que os recursos naturais são fontes básicas da economia, seja ela de mercado ou não. Numa educação para a Ecossocioeconomia, os sistemas sociais e econômicos devem estar conectados aos sistemas ecológicos, atentos aos seus limites.

\footnotetext{
${ }^{4}$ Nome dado à região histórico-cultural em que residem os bascos.
} 


\section{Considerações finais}

O cooperativismo de Mondragón possui um grande potencial para a investigação tecnológica aplicada à empresa, por meio de suas políticas de inovação e seus projetos de ciência e tecnologia. Atualmente conta com vários centros de pesquisa aplicada, um polo de inovação e uma universidade própria, com uma faculdade especializada em várias engenharias. A orientação destes recursos para a ecoeficiência é um dos desafios para o futuro. Fazer mais com menos. Menos energia e menos materiais.

Entretanto, este redirecionamento rumo à sustentabilidade requer uma mudança valorativa. A ascese religiosa da sua fundação e a racionalidade econômica, cuja noção de progresso e desenvolvimento reside no crescimento econômico do modelo atual, não podem ser facilmente tomadas de preocupação ambiental sem uma mudança de racionalidade, como sugere Leff (2001), isto é, a racionalidade ambiental prescinde da instrumentalidade que ela mesmo deseja superar. Portanto, mais que novas tecnologias, há a necessidade de uma profunda mudança cultural, da mesma forma que em qualquer outra organização econômica. Além da austeridade e frugalidade voluntária que construíram uma experiência de sucesso em termos socioeconômicos, Mondragón necessita agora incorporar novos valores de relação com o meio ambiente.

O termo sustentabilidade, bem compreendido, significa um novo paradigma, com a reestruturação de muitas coisas. Um desafio civilizatório, a base fundamental de novos sujeitos, de novas sociedades e novas economias. As suas implicações, portanto, são de longo alcance, sem espaço para cosméticos em termos tecnológicos.

\section{Referências}

ALTUNA Gabilondo, Larraitz (Coord.). La experiencia cooperativa de Mondragón: una síntesis general. Eskoriatza: Instituto Lanki, Universidad de Mondragón, 2008.

ALTUNA, Rafa; GRELLIER, Hervé; URTEAGA, Eguzki (Coord.). El fenómeno cooperativo en el mundo. Mondragón Bilduna: Economia Social y Cooperativismo. ETEO, UM, n. 1, 2008.
O cooperativismo de Mondragón, que começou como o cooperativismo da necessidade, tornou-se o cooperativismo da abundância, e esta é talvez uma de suas crises. Nesse sentido, é muito mais fácil pensar em uma adaptação do cooperativismo à sustentabilidade na sua origem, como aponta Azurmendi (1992), que nos tempos atuais. Mas além dos números, que cresceram muito, o que mais mudou a ponto de justificar tal afirmação?

A resposta a esta questão seguramente passa por aquilo que Weber (1999) definiu como gestão econômica e ação economicamente orientada, em que a primeira tem orientação primariamente econômica, no sentido de provisão, e a segunda é a invasão de outros campos da ação social pela economia (FERNANDES, 2008). Neste sentido, o futuro do cooperativismo de Mondragón dependerá, por um lado, do resgate de suas origens, não do ascetismo religioso e do antropocentrismo, mas das virtudes de que este ascetismo era portador, inclusive das suas possibilidades de adaptabilidade e equilíbrio com o meio ambiente apregoadas por Arizmendiarrieta. Por outro lado, precisa de um novo ascetismo da sustentabilidade, tal como sugerido anteriormente nas adaptações dos 10 princípios da Mondragón Corporação Cooperativa (MCC). Ao invés de fazer tudo neste mundo para salvar-se em outro mundo, fazer desta vida uma contínua ascese de salvação deste mundo, com bem apregoa Morin (1995) em seu capítulo "Evangelho da Perdição".

As lições do cooperativismo de Mondragón sobre o enfoque da ecossocioeconomia não são de fato sobre gestão socioambiental, mas sobre as possibilidades de construir um novo sujeito e uma nova sociedade. E nesse sentido, parafraseando Arizmendiarreta, mais que modelos de gestão ambiental e socioambiental, necessita-se de sujeitos que compreendam a noção de sustentabilidade, conjugando suas várias dimensões.

ANDERSON, Perry. Tras la huella del materialismo histórico. Madrid: Siglo XXI, 1986.

ARIZMENDIARRIETA, José María. La empresa para el hombre. Mondragón: Caja Laboral Popular, 1984.

AZKARRAGA Etxagibel, Joseba. Mondragón ante la globalización. La cultura cooperativa vasca ante el cambio de época. Eskoriatza: Instituto Lanki, 2007. 
AZURMENDI Otaegui, José. El hombre cooperativo: pensamiento de Arizmendiarrieta. Astaza (Otalora), 1992.

BERGER, P. L. Un mundo sin hogar. Modernización y consciencia. Santander: Sal Terrae, 1979.

COHEN, J.; ARATO, A. Civil society and political theory. Cambridge: MIT Press, 1992.

COSTA, Sérgio. Esfera pública, sociedade civil e movimentos sociais no Brasil. Novos Estudos do CEBRAP, São Paulo, n. 38, p. 38-52, mar. 1994

DOUROJEANNI, Axel. Reflexiones sobre estrategias territoriales para el desarrollo sostenible. Naciones Unidas, Comisión Económica para América Latina y el Caribe (CEPAL). Documento elaborado en la División de Medio Ambiente y Desarrollo, con ocasión de la Conferencia Cumbre sobre el desarrollo Sostenible, Santa Cruz, Bolivia, 7 y 8/diciembre, 1996.

FERNANDES, Valdir. A racionalização da vida como processo histórico: crítica à racionalidade econômica e ao industrialismo. Cadernos EBAPE.BR (FGV), v. 6, n. 3, set. 2008.

; SAMPAIO, C. A. C. Formulação de estratégias de desenvolvimento com base no conhecimento local. RAE Eletrônica, v. 5, 2006.

; _. Problemática ambiental ou problemática socioambiental? A natureza da relação sociedade meio ambiente. Curitiba: UFPR, Revista Eletrônica de Meio Ambiente e Desenvolvimento, v. 18, 2008.

FISCHER, Tânia (Org.). Poder local: governo e cidadania. Rio de Janeiro: FGV, 1993.

GUERRA A., Pableo. Economía y ecología: hacia una socioeconomía solidaria, 2007. Disponível em: <http://www. economiasolidaria.net/biblioteca/econmia.php $>$. Acesso em: 04/12/2009.

HABERMAS, J. Sabedoria popular como procedimento. CEBRAP, São Paulo, n. 26, p.100-113, 1990.

KAPP, K. W. The social costs of business enterprise. Nottingham: Spokesman Books, 1963.

LEFF, Enrique. Epistemologia ambiental. São Paulo: Cortez, 2001.

LÉVY, P. A inteligência coletiva. São Paulo: Loyola, 1998.

LISBOA, Armando de Melo. Economia solidária e autogestão: imprecisões e limites. $R A E$, v. 45, n. 3, p. 109-115, jul./ set. 2005 .
MANTOVANELI JR., O.; SAMPAIO, C. A. C. Princípios para a governança no ecodesenvolvimento. In: EnANPAD, 30., 2006, Salvador. Anais... Rio de Janeiro, 2006.

MAX-NEEF, Manfred et al. Economía descalza: señales el mundo invisible. Estocolmo, Buenos Aires, Montevideo: Editorial Nordan Comunidad, 1986.

MCC, MONDRAGÓN Corporación Cooperativa. Día de Don José María. Mondragón: MCC, 2006.

MORIN, Edgar. Terra-pátria. Porto Alegre: Sulina, 1995.

RAMOS, Alberto Guerreiro. A nova ciência das organizações: uma reconceituação da riqueza das nações. Rio de Janeiro: Fundação Getulio Vargas, 1989.

RAZETO, Luis. O papel central do trabalho e a economia de solidariedade. Proposta, v. 75, p. 91-99, dez. 1996/fev. 1997.

SACHS, Ignacy. Ecodesenvolvimento: crescer sem destruir. São Paulo: Vértice, 1986a.

. Espaços, tempos e estratégias do desenvolvimento. São Paulo: Vértice, 1986b.

SAMPAIO, C. A. C. Gestão organizacional estratégica para o desenvolvimento sustentável. Itajaí: Editora da UNIVALI, 2000 .

. A construção de um modelo de gestão que o promove o desenvolvimento sustentável. Cadernos Ebape (FGV-RJ), Rio de Janeiro, n. 5, 2004.

Gestão que privilegia uma outra economia: ecossocioeconomia nas organizações. Blumenau: Edifurb, 2010. No prelo.

SANTOS, Milton. Metamorfose do espaço urbano. São Paulo: Hucitec, 1994.

; SOUZA, Maria Adélia A. de; SILVEIRA, Maria Laura. (Org.). Território: globalização e fragmentação. São Paulo: Hucitec/Annablume, 2002.

SINGER, Paul. Introdução à economia solidária. São Paulo: Editora Fundação Perseu Abramo, 2002.

WEBER, Max. Economia e sociedade: fundamentos da sociologia compreensiva. v. 1. Brasília: UnB, 1999.

Recebido em fevereiro de 2012. Aceito em maio de 2012. Publicado em junho de 2012. 